\section{Allergieprävention durch $\mathrm{H}_{1}-\mathrm{Blocker}$}

\author{
$\mathrm{H}_{1}$-Blocker zeigen eine Reihe von immunmodulatorischen Effekten. \\ Sie schützen damit nicht nur vor den Symptomen akuter Über- \\ empfindlichkeitssreaktionen, sondern beeinflussen auch die \\ primäre Immunantwort. Die sich daraus ergebende Möglichkeit \\ eines präventiven Einsatzes wurde im Tierversuch näher untersucht.
}

Die Sensibilisierung führte zu einem signifikanten Anstieg der Serumspiegel von Gesamt-IgE und IgG, sowie in vitro zu einer gesteigerten IL-5- und IL-4-Synthese von Zellen aus Milz und peribronchialen Lymphknoten. Außerdem reagierten die sensibilisierten und bronchial provozierten Mäuse mit einer starken eosinophilen Infiltration des Lungengewebes und entwickelten eine Atemwegshyperreaktivität gegenüber inhaliertem Metacholin. Die Gabe des H1-Blockers vor der Sensibilisierung konnte alle diese Reaktionen unterdrücken. Die antiallergischen Wirkungen waren schon in der niedrigen Dosierung von $0,01 \mu \mathrm{g}$ Desloratadin pro Maus zu erkennen. Daraus könnte abgeleitet werden, dass die beobachteten Effekte des H1-Blockers außer durch die Blockade von H1-Rezeptoren auch direkt, z. B. durch eine Beeinflussung von Antigen-präsentierenden Zellen oder eine Expressionsmodulation von Chemokinen oder Adhäsionsmolekülen, zustande kommen.

Fazit: Im Tierexperiment kann durch die Gabe eines H1-Blockers die experimentell induzierte Sensibilisierung sowie die Entwicklung einer bronchialen Entzündungsreaktion und Hyperreaktivität reduziert werden. Ein allergiepräventiver Einsatz dieser Substanzgruppe ist daher durchaus in Erwägung zu ziehen - und wurde auch bereits in Interventionsstudien wie der ETAC-Studie mit Erfolg praktiziert.

$b k$

Blümchen K et al. Oral administration of desloratadine prior to sensitization prevents allergen-induced airway inflammation and hyper-reactivity in mice. Clin Exp Allergy 2004; 34: 1124-30

\title{
Würmer induzieren Schutz durch IL-10
}

\section{Als ein Grund für die Zunahme von Allergien wird der Rückgang von bakteriellen und parasitären Infektionen in der Kindheit diskutiert. Besonders auffällig ist dieser Zusammenhang bei Wurm- infektionen. Einen Anhaltspunkt für den immunologischen Mechanismus eines protektiven Einflusses lieferten Experimente mit Bilharziose-infizierten Mäusen.}

$\mathrm{n}$ n einer niederländischen Studie wurden Mäuse mit dem in Afrika und Südamerika heimischen Pärchenegel Schistosoma mansoni, dem Erreger der Darmschistosomiasis beim Menschen, infiziert. Die Wissenschaftler konnten zeigen, dass bei den Wurm-infizierten Mäusen keine experimentelle Anaphylaxie ausgelöst werden konnte. Vermittelt wurde der Schutz durch IL-10-produzierende BZellen, deren Bildung durch die Parasiteninfektion induziert wurde. Blockierte man die B-Zellen oder IL-10, war die Anfälligkeit der Mäuse für die Entwicklung einer anaphylaktischen Reaktion nach Allergenprovokation erhöht.

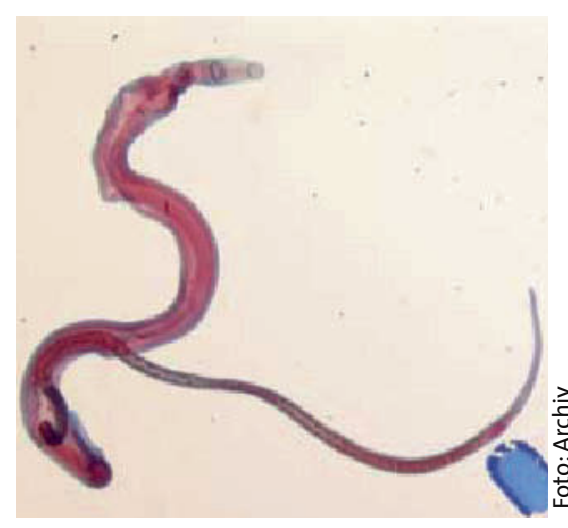

Schistosoma mansoni: Das fadenförmige Männchen (rechts) liegt in einer ventralen Rinne des Weibchens.
Dies zeigt die Bedeutung der immunologischen Schutzwirkung von IL10 -produzierenden B-Zellen, denn die Pärchenegel induzieren eigentlich eine starke TH2-Zytokinreaktion, verbunden mit einer erhöhten Synthese von IgE und einer Eosinophilie. Der Wurm ist also offensichtlich in der Lage, bei seinem Wirt einen TH1-/TH2-Switch $\mathrm{zu}$ induzieren und ihn damit atopisch werden zu lassen, schützt ihn aber gleichzeitig vor einer Allergie durch Induktion von B-Zell-produziertem IL10.

Fazit: Wurminfektionen verschieben zwar die Immunreaktion in Richtung einer TH2-Zytokinantwort, führen aber gleichzeitig durch die Induktion von IL-10 zu einem Schutz vor Allergie.

$b k$

Mangan NE et al. Helminth infection protects mice from anaphylaxis via IL-10producing B cells. J Immunol 2004; 173: 6346-56 